\section{Experience counts}

\section{RicARDO ARAYA}

Academic Unit of Psychiatry, University of Bristol, Cotham House, Cotham Hill, Bristol BS6 6JL, UK

Thornicroft et al share with us their knowledge and experience in developing community mental health services for several decades. Their focus is on how best to use the accumulated experience in this process. In an era in which only hard evidence extracted from well designed studies seems to count, it is refreshing to read a paper in which experience is presented as a valuable resource.

Experience as a general concept comprises knowledge usually acquired through involvement or exposure to something. As such it is not subject to the rigour of the scientific method used to generate the knowledge in line with the emergent evidence-based movement in medicine. Some of the limitations of the scientific evidence have helped to increase the relative importance of the value given to experience in our decision making process. Scientific evidence can be flawed, not only because of lack of rigor but also because of other practices leading to publication bias (1-3). Besides, most medical dilemmas still remain scientifically unresolved and published scientific papers arising from the developing world are virtually non-existent (4). So, experience might have a larger place informing important decisions, especially where there is no hard, scientific evidence. Undoubtedly there is a need to improve our methods to systematize the information obtained from experiences so that their relative value can be more accurately assessed.

Primary care services are not mentioned explicitly by Thornicroft et al in the list of key services that a comprehensive general adult mental health care system should have. Although the authors might have thought of these services as outpatient or ambulatory facilities, it may be better to highlight these services more prominently. According to the authors, World Health Organizations (WHO)'s advice can be powerful ammunition to sell changes to hard-to-convince people.
In a recent speech for the Fourth Global Meeting of Heads of WHO Country Offices, the WHO Director General, Margaret Chan, repeated a call to return to primary care as the key sector to strengthen health services throughout the world.

It is interesting to note the advice given not to delay the reduction of long-stay hospitals, because the main or only source of funds for community services would be from savings made as large hospitals are reduced in size. Rationally it is difficult to disagree with this point; however, reality is much more complex than this and often defies rationality. Take for instance the case of Brazil, a large country where there is an ongoing reform of psychiatric services (5), one of whose aims is to reduce the number of beds in large psychiatric hospitals. There is a heated debate at present because some experts claim that the funds saved from these closures are not being re-invested in mental health services $(6,7)$. The destiny of saved resources is often uncertain and delays may be advisable in order to clarify the ultimate destiny of saved resources. This process often takes time and requires strong political alliances and lengthy negotiations with many stakeholders. Later in the paper we are warned that changes take time, something that most people involved with improving health services in the developing world would agree with (8).

The authors also wisely warn us that a rapid shift of resources can produce unstable and confused new clinical services unable to offer good care. There are many examples of this situation in developed and developing countries. For instance, the Chilean government introduced a ground-breaking programme that offers a state guarantee to every citizen suffering from depression that timely and adequate treatment will be available (4). Private health insurance schemes have to adhere to this ruling too. One of the implications of this wonderful change has been that many of those psychiatrists who were still working in the state sector have now moved to the private sector, which needs more professionals to cater for an increased demand. State mental health clinics have been deprived of vital resources and are struggling to deliver adequate care.

Although I doubt anyone will disagree with the idea of greater participation of users and carers deciding upon priorities, my experience is that there is still little real participation in most parts of the world. Decisions are made at the top, but some form of "protected participation" is offered, often merely to satisfy political correctness. The authors wisely advise us that we should try to persuade governments to fund participation, but nobody should be under any illusion that this will be a short and easy process.

When it comes to challenges, some of the advice needs to be carefully adapted to the local context where it may be applied. Some of the suggestions, such as assuring people that there will be no redundancies, are impossible to offer in many parts of the developing world. Similarly, calming anxiety with "regular staff group and individual supervision meetings, regular clinical case review meetings, and periodic forms of audit or self-appraisal on the performance of the clinical team" may be an impossible recipe for most poor countries in the world. However, the general idea I extract from this advice is that more and better communication, and increased real participation of those involved in the change, may help.

How to manage opposition is another interesting section. The authors advised on wide consultation previously in the paper and this could help to decrease opposition. However, changes are often centrally led with little prior debate, and opposition is just but the natural consequence. Personally, I would have preferred to hear more about the vast experience of the authors in persuading people rather than dealing with the opposition. It can be rather irritating when one is invited to a process of consultation whose ultimate decision seems already made. Other than the reasons given by the authors, I have come across people who do not want changes because it is against their own interests. For instance, a consultant who has spent years setting up a successful inpatient unit may have little interest to start all over again. In such circumstances, 
advice given to outmanoeuvre opposition is essential.

Since the paper focuses on experience rather than evidence, it would have been most informative to hear more about the authors' experiences and advice on how to deal with political and other vested interests. Taking advantage of political opportunities and/or forging alliances with powerful players may be critical to introduce changes in many parts of the world. Changes can also be used to obtain quick political gains or reposition political forces. Likewise, I would have liked to hear more about the powerful influence of the media and in particular public scandals to promote changes. Horrible pictures of unacceptable human right abuses widely publicised in newspapers or journals may have made larger contributions to the improvement of mental health services than any other wellthought document in many countries throughout the world. For instance, the acceptance of some countries into the European Union was made conditional upon rectifying some of such abuses. Finally, the other thing on my wish list for the next version of this paper would be something about the role and importance of leadership in the process of developing or improving health services. The authors are leaders in the field and it is something to which they can contribute greatly with their experience.

Of course space is limited and it is commendable that such a vast experience was condensed in this paper, full of the wisdom obtained through a life dedicated to this field. It is particularly refreshing to read this paper because it returns some value to experience, often rapidly dismissed but also the only support available to reach critical decisions in many countries where hard evidence through research is still a dream.

\section{References}

1. Ioannidis JP. Why most published research findings are false. PLoS Med 2005;2:e124.

2. Fava GA. Financial conflicts of interest in psychiatry. World Psychiatry 2007;6:19-24.

3. Turner EH, Matthews AM, Linardatos E et al. Selective publication of antidepressant trials and its influence on apparent efficacy.
N Engl J Med 2008;358:252-60.

4. Patel V, Araya R, Chatterjee S et al. Treatment and prevention of mental disorders in low income and middle income countries. Lancet 2007;370:991-1005.

5. Ministério da Saúde, Secretaria de Atenção à Saúde/DAPE. Saúde Mental no SUS: acesso ao tratamento e mudança do modelo de atenção. Relatório de Gestão 20032006. Brazilia: Ministério de Saude, 2007.
6. Andreoli S, Almeida-Filho N, Martin D et al. É a reforma psiquiátrica uma estratégia para reduzir o orçamento da saúde mental? O caso do Brasil. Rev Bras Psiquiatr 2007;29:43-6.

7. Gentil V. More for the same? Rev Bras Psiquiatr 2007;29:188-9.

8. Berwick D. Lessons from developing nations on improving health care. BMJ 2004; 328:1124-9. 